\title{
Quality Guarantee of Graduate Education in China: A Bibliometric Study
}

\author{
Pengbin Gao*, Yiduo Song, Xue Li, Hongjin Lin \\ School of Economics and Management \\ Harbin Institute of Technology \\ Weihai, China
}

\begin{abstract}
Education quality has become an attracting topic in postgraduate education in past few decades. Although many scholars have carried out a wide range of research, the research did not provide a chronological picture of the themes. To give a comprehensive picture of quality guarantee of China's graduate education, bibliometrics analysis methods were employed to analyze the 342 articles collected from China National Knowledge Infrastructure (CNKI) between 1999 and 2019. The distribution characteristics of documents, published journals, research institutions and research methods were revealed in content analysis. The law of change on research field and research topics was described in co-word analysis with VOSviewer. Based on the results, this study also suggests directions for further work.
\end{abstract}

Keywords-quality guarantee; China's graduate education; bibliometric analysis; co-word analysis; VOSviewer

\section{INTRODUCTION}

After more than 40 years of development, China's graduate education has initially formed the certain training model with Chinese characteristics. According to statistics, by 2018 there are 2.73 billion graduates, which include 389.5 million doctoral degree candidates and 2.34 million master degree candidates. The state has attached great importance to the quality of postgraduate education and taken many measures to continuously improve the quality assurance system, which promotes the healthy and smooth development of graduate education. In April 2013, Ministry of Education, National Development and Reform Commission and Ministry of Finance jointly issued Opinions on Deepening the Reform of Postgraduate Education, which clearly regard the overall construction of quality assurance system as one of the key points of intensive development. Accordingly, numerous studies have increased considerably and many topics have been discussed.

Some scholars analyzed and gave some advice to promote the quality of graduate education. Abiddin et.al (2013) suggested that Institutions should enhance the quality of higher education for graduate research students developing distinguished human capital ${ }^{[1]}$. Doran et.al (2014) pointed out that the higher quality graduate training experience can play an important role in promoting student's development ${ }^{[2]}$. Li et.al (2016) suggested that

This work was supported by the Research Project of Postgraduate Education and Teaching Reform in Harbin Institute of Technology (Weihai)
ISO9000 can promote the construction of graduate education quality management systems ${ }^{[3]}$. Verma (2016) modified quality model to improve service quality of Govt. Degree college ${ }^{[4]}$.

Some scholars analyzed and evaluated the quality of education and its effects. Peña et al (2012) pointed out the high quality thesis advising plays an important role in success of graduate students writing research papers ${ }^{[5]}$. Wamala et al (2013) suggested that the introduction of the examination can enhances the quality of education outcomes $^{[6]}$. Safargaliev et al (2015) set a synthesized model and used a quality assessment method of academic training of graduates ${ }^{[7]}$. Belecina and Ocampo (2017) thought that the tracer study can be used for the enhancement of quality course programs offered in higher education institutions ${ }^{[8]}$. In addition, Stevenson (2016) estimated the monetary return to quality in US graduate education ${ }^{[9]}$.

Given the above literature, numerous reviews have provided various research issues from different perspectives, but these researches were more dependent on subjective analysis and can't disclose precisely the nature of the field. Specifically, this study adopted the quantitative method to analyze the domain as a whole.

\section{RESEARCH DESIGN}

\section{A. Research Method}

Content analysis is a systematic and quantitative method, which can give a comprehensive description of the status of information from literature. The key processes of content analysis include determining the analysis unit and analyzing the categories. In this paper, year, journals, institutions and research types were used to analyze the distribution of papers. In addition, research content was also analyzed.

Co-word analysis draws upon the assumption that a paper's keywords can give an adequate description of content. VOSviewer is a software tool for constructing and visualizing bibliometric maps. Unlike most computer programs that are used for bibliometric mapping, VOSviewer is especially useful for displaying large bibliometric maps in an easy-to-interpret way, and pay more attention to drawing and clustering. So we hope to use it to 
make a clearer and richer keyword co-occurrence analysis of undergraduate research.

\section{B. Data Collection}

The data were collected through a set of procedures. First, China National Knowledge Infrastructure (CNKI) database was selected as the data source. Second, according to the purpose of this study, the search criteria were formulated by including "quality guarantee" and "postgraduate education". The data were extracted in June 2019, with the search in the topic field covering the period from 1999 to 2019. Finally, a total of 342 articles were retrieved and selected as the analysis sample.

\section{RESULTS OF CONTENT ANALYSIS}

\section{A. Number of papers}

After analyzing the literature collection of quality guarantee of graduate education from the CNKI database, the publication growth from 1999 to 2019 was shown in Fig. 1. There has been a steady increase since 1999 and the quantity reached to a high tide in 2019.

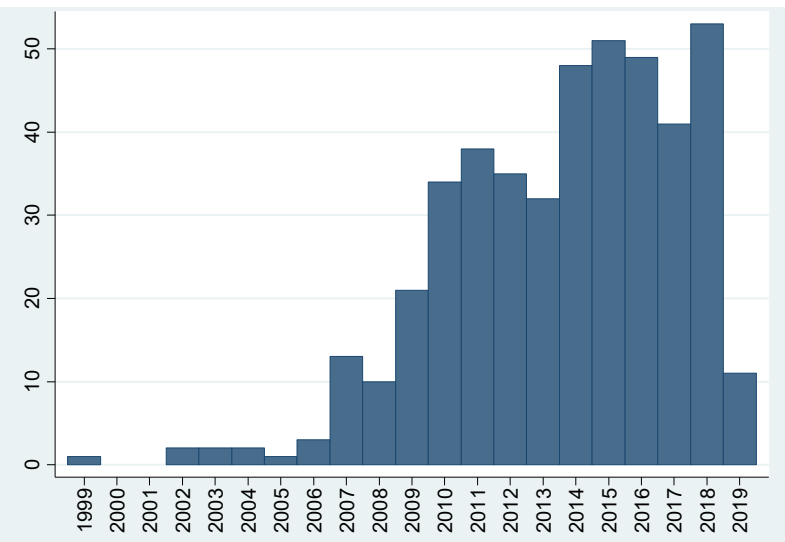

Fig. 1. Growth of literature over time

\section{B. The distribution of journals}

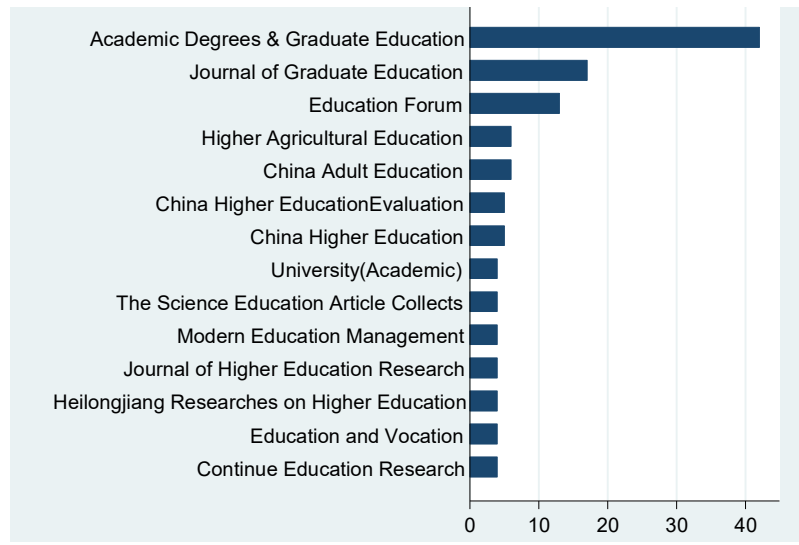

Fig. 2. Distribution of top 14 journals

From 1999 to 2019, 186 journals contributed 342 articles. We ranked journals on their total contribution to the list of articles. The top 14 journals with the largest number of publications were identified, which is presented in Fig.2. At the same time, the annual publication of top 7 journals is shown in Fig 3. Most of them are educational journals; Academic Degrees \& Graduate Education is the journal with the highest number of papers, followed by Journal of Graduate Education and Education Forum.

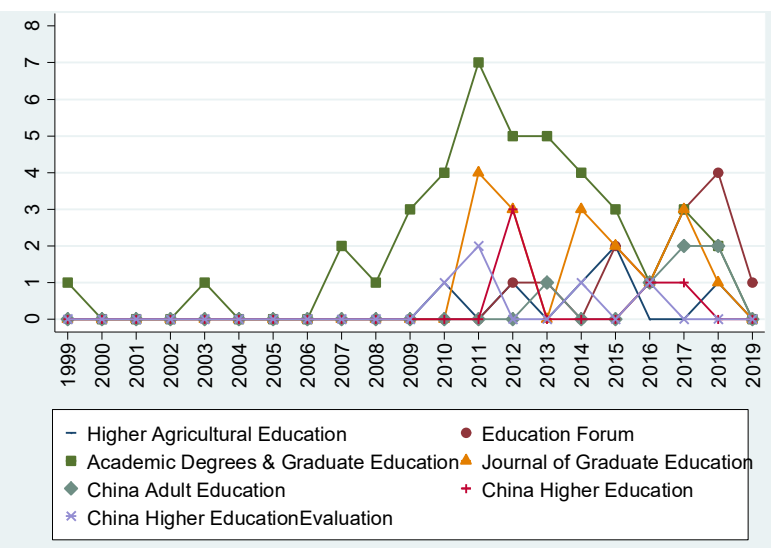

Fig. 3. Leading journals contributors

\section{The distribution of institutions}

During the 20 year period of the study, the 342 first authors were affiliated with 193 institutions.

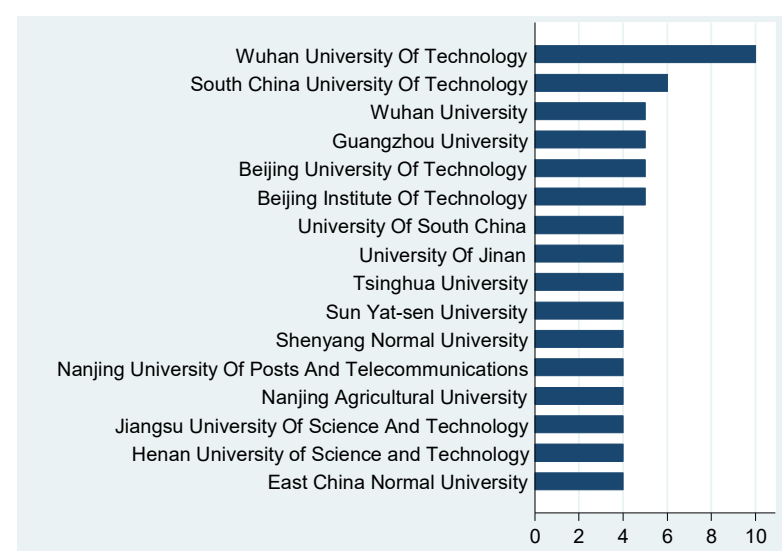

Fig. 4. Main institutions

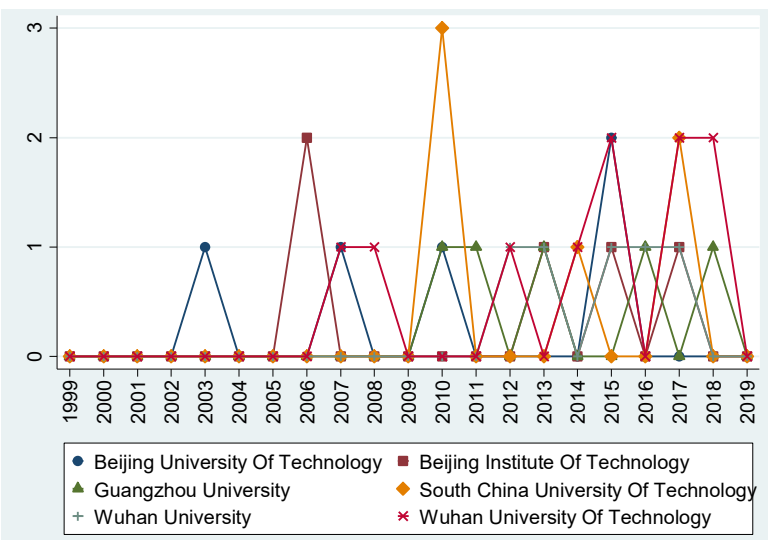

Fig. 5. Leading institutions contributors 
The top 16 universities are ranked in Fig. 4, and the annual publication of top 6 journals is shown in Fig 5 . according to the Figure 4 and Figure 5, Wuhan University Of Technology is the institution with the highest number of papers, followed by South China University Of Technology and Wuhan University. It is suggested that top universities usually pay more attention to the quality of graduate education.

\section{The distribution of research methods}

As concerning research type and methodology, we distinguished among theoretical, case, review and empirical contributions, which are presented in Fig.6.

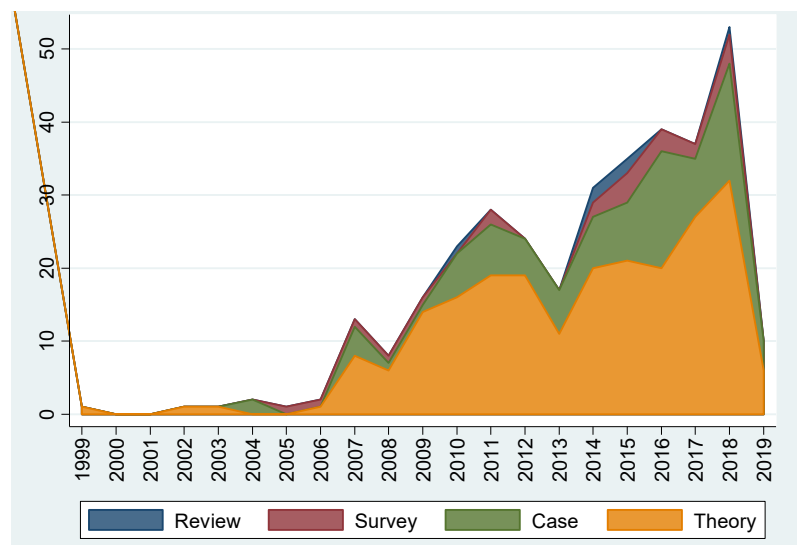

Fig. 6. Frequencies of research types

According to the result of Figure 6, there are more theoretical researches from 1999 to 2019, which suggests this method is main form. At the same time, survey and case researches began to increase in 2003 gradually.

\section{RESUlTS OF CO-WORDS ANALYSIS}

Generally, searching keywords for research papers is a convenient way to retrieve data for studying a research field. Using the VOSviewer 1.6.11, this paper also conducted the statistical analysis of keywords, demonstrating the most popular research topics.

\section{A. Cluster analysis}

The Fig. 7 visualized the relationships among the highfrequency keywords (over 5). The study categorized those keywords that appeared multiple times into four themes. The first cluster focused on system construction, including Construction, Internal Quality Assurance System, External Quality Assurance, Quality Assurance Mechanism. The second cluster focused on Dissertation and Evaluation. The third cluster focused on the professional degree, including Clinical Medicine, Training, Full-time. The fourth cluster focused on the capability and system, including Training Quality, Guarantee System, Education Quality, Innovation, Guarantee Mechanism.

\section{B. Hot topics}

According to the Fig. 8, beginning with 2012, the most prevalent keywords were "teaching quality", "external quality assurance". In 2016, the most prevalent keywords were "professional degree" and "professional degree graduates", reflecting on the changing trends in the period of 1999-2019.

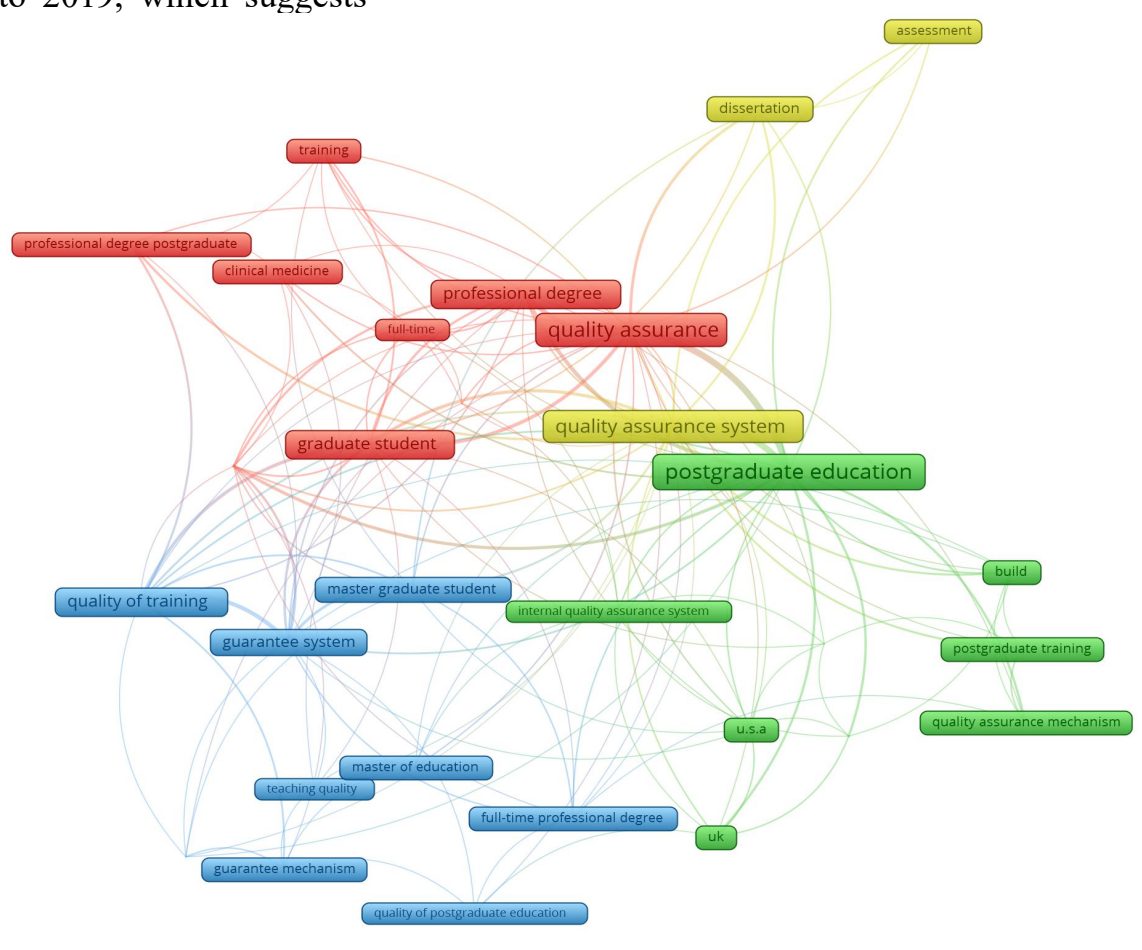

Fig. 7. Keyword co-occurrence network 


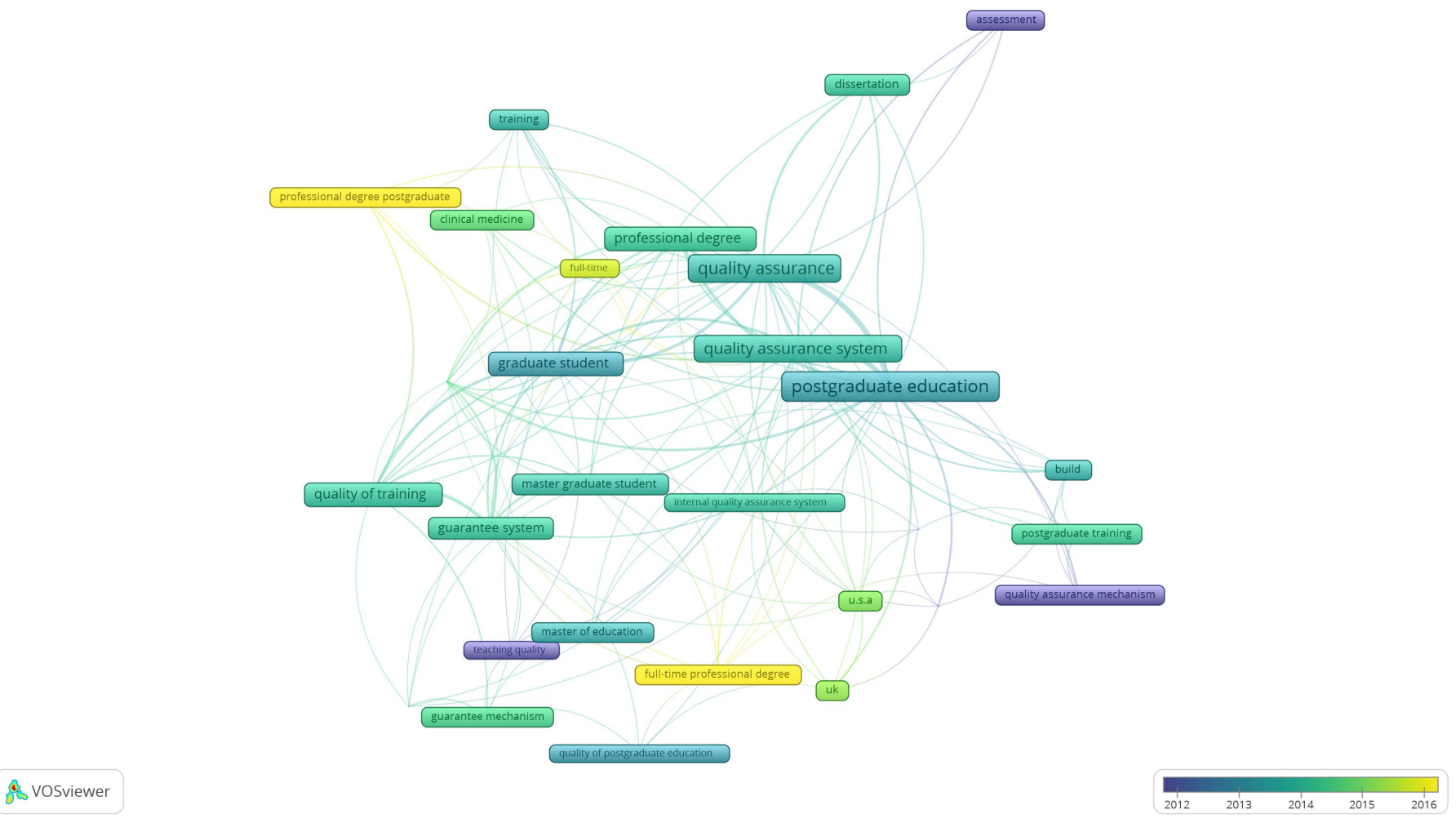

Fig. 8. Overlay visualization of keyword co-occurrence based on year of publication

\section{CONCLUSION}

Based on bibliometrics and co-words analysis, this study produced a reasonable result. This study can analyze the characteristics and trends of the previous studies, and describe systematically development situation, which can give reference for other researches.

The results of co-word analysis show that the research focuses mainly on the system construction, evaluation, professional degree and capability and so on.

Our study has got some valuable conclusion, but it is not free from limitation. In the future, we can enlarge the sources of publication and use other quantitative approaches to learn more about the intellectual structure of research of quality assurance in China's graduate education.

\section{ACKNOWLEDGMENT}

This work was supported by the Research Project of Postgraduate Education and Teaching Reform in Harbin Institute of Technology (Weihai).

\section{REFERENCES}

[1] Abiddin N Z, Ismail A, Taniredja T. Enhancing Quality of Higher Education for Graduate Research Students Development[J]. Educare, 2013, 5(2).

[2] Doran J M, Meyerson D A, El-Ghoroury N H. Promoting a higher quality graduate training experience: A student perspective on the HSPEC Blueprint for Health Service Psychology Education and Training[J]. Training and Education in Professional Psychology, 2014 8(1): 12 .

[3] Hewei L I, Sun Y. Construction of the ISO9000 family of standardsbased graduate education quality management system $[\mathrm{J}]$. Chinese Journal of Medical Education Research, 2016, 15(4): 325-328

[4] Verma G R. Achieving Quality in Higher Education: Road to Academic Excellence in Graduate and Post-Graduate Institution of Jammu and Kashmir[J]. ZENITH International Journal of Multidisciplinary Research, 2016, 6(3): 70-82.

[5] Peña III S C D, Gersana Z, Tolod L, et al. Quality of thesis advising in graduate education in Northern Mindanao[J]. Liceo Journal of Higher Education Research, 2012, 8(1): 1-1.

[6] Wamala R, Buyinza M. Quality of Education Outcomes: The Role of the Graduate Management Admission Test[J]. American Journal of Business Education, 2013, 6(1): 141-148.

[7] Safargaliev E R, Eremina I I, Konstantinovich S S, et al. Mathematica Model and Qualimetric Assessment of Graduate Education Quality in Environment Saturated with Information and Communication Technologies[J]. International Education Studies, 2015, 8(2): 78-83.

[8] Belecina R R, Ocampo Jr J M. Towards Quality Graduate Mathematics Teacher Education: A PNU CGSTER Tracer Study[J]. SOSIOHUMANIKA, 2017, 10(1): 45-56.

[9] Stevenson A. The returns to quality in graduate education[J]. Education Economics, 2016, 24(5): 445-464 